\title{
DJANGO LIVRE: DO CINEMA PARA OS QUADRINHOS, UMA TRADUÇÃO INTERSEMIÓTICA
}

\section{Django Unchained: from cinema to comics, an intersemiotic translation}

\author{
Mariana de Souza COUTINHO${ }^{1}$ \\ Renata Ciampone MANCINI ${ }^{2}$
}

Resumo: A forte presença de adaptações no tecido cultural contemporâneo convida o olhar analítico a contemplar com mais atenção as estratégias subjacentes aos processos de adaptação, aqui entendidos como traduções intersemióticas. Este artigo se ocupa da adaptação de Django Livre (2012), do diretor Quentin Tarantino, para uma série de sete revistas em quadrinhos. Chama a atenção a direção pouco usual desse processo, que parte do cinema para as histórias em quadrinhos. Nossa análise aplica conceitos da semiótica francesa, especialmente em sua abordagem tensiva, para explorar questões rítmicas ligadas às estratégias de adaptação. Faremos uma análise comparativa das obras a partir de um parâmetro rítmico, que relaciona as transições de quadros (MCCLOUD, 1995) com a montagem da linguagem cinematográfica.

Palavras-chave: Adaptação. Semiótica. Django livre. Tradução intersemiótica. Quadrinhos. Cinema.
Abstract:Thestrongpresenceofadaptations in the contemporary cultural sphere invites an analytical view to contemplate with more attention the strategies underlying the processes of adaptation, here conceived as intersemiotic translation. This article presents an analysis of Django Unchained (2012), by director Quentin Tarantino, adapted for a series of seven comic books. It is worth noting the unusual direction of this process, which starts from the cinema to the comics. Our analysis applies concepts of French semiotics, especially in its tensive approach, to explore rhythmic issues linked to adaptation strategies. We propose a comparative analysis of the works relying on a rhythmic parameter that relates the transitions of comic frames to the editing strategies (MCCLOUD, 1995) in the cinematographic language.

Keywords: Adaptation. Semiotics. Django unchained. Intersemiotic translation. Comics. Cinema.

1 Coutinho. UFF. E-mail: marianacoutinho16@gmail.com. ORCID ID: https://orcid.org/0000-0003-34864571 
- Django livre: do cinema para os quadrinhos, uma tradução intersemiótica

Super-heróis dos quadrinhos adquirem três dimensões no cinema. Clássicos personagens literários ganham cores nos traços de uma história em quadrinhos (HQ). Carismáticas figuras da sétima arte transformam-se em avatares nos jogos eletrônicos. As adaptações entre linguagens ocupam lugar de destaque nas práticas contemporâneas, não apenas nos processos de produção artística e de entretenimento, mas também na criação de objetos com fins didáticos. Nesse contexto, um olhar voltado para o que aqui trataremos como traduções intersemióticas ganha relevância e atualidade.

Propomos, neste artigo, a análise de um objeto cujo caminho de tradução intersemiótica é pouco usual: a adaptação do filme Django Livre (2012), do diretor Quentin Tarantino, para os quadrinhos produzidos pela DC Comics, assinados por Reginald Hudlin, com arte de R. M. Guéra, Denys Cowan, John Floyd e Danijel Zezelj. Nosso principal interesse recai sobre as estratégias de construção de sentido na obra adaptada, tomando por base as estratégias do filme, procurando relacioná-las à lógica mercadológica de lançamento do filme e das HQs.

A primeira história da série foi apresentada alguns dias antes do lançamento do filme. A trajetória do escravo Django é contada em sete volumes de histórias em quadrinhos, lançados entre dezembro de 2012 e meados de 2013. Toda a série é baseada no filme e no roteiro original escrito por Tarantino. Como o próprio roteirista e diretor anuncia na contracapa da revista, na HQ há algumas cenas que foram cortadas do filme, mas que aparecem no roteiro original.

Em uma rápida observação das revistas, algumas questões já chamam nossa atenção. Os quadrinhos são vendidos como uma extensão do filme. Frases de destaque nas capas anunciam: "Baseado no roteiro de Quentin Tarantino" e "Indicado ao Oscar de Melhor Filme e de Melhor Roteiro Original". O indicado ao prêmio da Academia, claro, foi o filme e não a $\mathrm{HQ}$, mas parece-nos que o enunciador dos quadrinhos quis tratar os dois como um único produto.

O enunciador dos quadrinhos Django Unchained parece investir em estratégias enunciativas para aproximá-lo não só do conteúdo do filme, mas da própria linguagem cinematográfica. Tal procedimento é evidenciado pelo fato de as HQs terem sido lançadas simultaneamente ao filme e por se pretenderem como uma extensão deste para um público que não necessariamente é fã de quadrinhos, mas que é fã de cinema e, mais precisamente, fã de Tarantino.

Nesse contexto, será necessário pensar em alguns elementos da linguagem cinematográfica a fim de estabelecer um ponto de partida da adaptação para HQs, comparando questões rítmicas, em especial no que se refere ao desenvolvimento das 
ações - o que, no cinema, se traduz principalmente na montagem; e, nos quadrinhos, nas transições entre quadros.

Nesse âmbito, nossa atenção recai sobre a gestão rítmica de ambos os textos. Como entender o ritmo na passagem de uma linguagem para outra, quando as características de partida dessas linguagens já apresentam uma rede de possibilidades rítmicas diferentes? Qual é a estratégia empregada pelo enunciador da obra de chegada?

Vemos, portanto, que a análise dessa adaptação nos coloca questões relacionadas não apenas à tradução do conteúdo de Django Livre, mas também, em outra dimensão, à tradução entre as linguagens do cinema e dos quadrinhos, levando em conta seus planos de expressão e as características próprias de cada uma. Nesses termos, como a linguagem da obra de partida interfere na forma final da obra adaptada?

Por terem planos de expressão diferentes, as diversas linguagens possuem características próprias que as constituem enquanto sistemas estáveis, porém, ao mesmo tempo, vivos, que se modificam com o tempo e incorporam novos usos e novas possibilidades. Assim acontece com o cinema e também com as histórias em quadrinhos. Neste artigo, no entanto, optamos por uma abordagem sincrônica, que busca analisar algumas características desses dois sistemas para estabelecer uma base de comparação entre os textos original e adaptado.

Vale destacar que, quando falamos da linguagem cinematográfica e da linguagem em quadrinhos, compreendemos principalmente os usos mais difundidos e sedimentados, como é o caso do cinema hollywoodiano canônico e de certa estrutura reiterada de quadrinhos ocidentais mais populares, como os de super-heróis, por exemplo. Essa abordagem nos parece razoável, dado que nosso recorte centrou-se em dois objetos que se enquadram nessas formas de vida (FONTANILLE, 2015) mais estáveis e centrais.

Quando pensamos em um sistema, concebemos uma rede de possibilidades estabelecidas. O esperado de um texto enquanto processo é a atualização de certos elementos desse paradigma estabelecido. Contudo, podemos pensar que alguns elementos são mais mobilizados do que outros e criam uma maior expectativa de uso. Por exemplo, em uma história em quadrinhos, é esperado que sejam usados balões de fala, mas nada impede que o enunciador opte por trazer os textos fora desse formato. Os balões já compõem um uso esperado, que seguiria, por isso, uma lógica implicativa (se... então), ao contrário da concessiva (embora...) (ZILBERBERG, 2011).

A relação entre implicação e concessão diz respeito diretamente ao andamento de um texto. Entendemos as estratégias compreendidas por uma lógica concessiva como 
- Django livre: do cinema para os quadrinhos, uma tradução intersemiótica

saliências perceptivas, aumentos de intensidade e, portanto, elementos de aceleração (ZILBERBERG,2011). Em vista de uma concessão, o enunciatário de um texto se vêimpactado, ao contrário do que acontece quando é persuadido por uma lógica implicativa, em que não há estranhamento. Ele se depara apenas com o que já é reconhecível ou esperado. Neste caso, dizemos que o andamento é desacelerado.

A partir dessa base teórica, seguiremos um protocolo de análise, em um primeiro momento, explorando as estratégias de adaptação do filme para as histórias em quadrinhos, para, em seguida, tratar das diferentes características das linguagens envolvidas.

\section{Django, do filme à tradução}

No sul dos Estados Unidos, no século XIX, o escravo Django é comprado pelo exdentista e caçador de recompensas alemão King Schultz, que lhe oferece a liberdade em troca de alguns meses como ajudante na caça a bandidos procurados. Depois de aprender a manejar armas e preparar estratégias para capturar foragidos com o alemão, Django parte para uma nova missão: encontrar sua esposa, Broomhilda, que ainda é escrava. Após descobrir que ela foi comprada por Monsieur Candie e agora vive na fazenda Candyland, Django planeja uma estratégia para libertá-la, partindo para a fazenda na companhia de Schultz. Lá, ele precisará se desvencilhar das desconfianças do escravo Stephen para levar seu plano adiante.

Os quadrinhos adaptam a mesma história descrita no roteiro de Tarantino. Observamos que as figuras do filme se repetem e estão recobrindo os mesmos temas. A opressão, um dos temas centrais da história, é relacionada com a isotopia da violência, figurativizada por várias cenas de açoite e tortura ${ }^{3}$, concretizando a opressão do sistema escravocrata - passagens que estão presentes também nos quadrinhos.

Essas figuras são apresentadas principalmente nos flashbacks ${ }^{4}$, ou seja, em um momento de referência passado. Do ponto de vista tensivo (ZILBERBERG, 2011), o tema da violência, concretizado em momentos de crueldade (as lutas de mandingo ${ }^{5}$, o escravo D'Artangnan sendo devorado por cachorros, Broomhilda presa em uma caixa de madeira enterrada no jardim, Django e outros escravos sendo açoitados, etc.), provoca

\footnotetext{
3 Para a semiótica francesa, é por meio dos temas e das figuras que acessamos o nível discursivo, mais superficial, de um texto. As figuras são elementos que concretizam temas. A isotopia diz respeito a uma reiteração de traços semânticos que constrói certos caminhos de leitura (BARROS, 2010).

$4 \mathrm{Na}$ linguagem cinematográfica, oflashback é uma " cena que revela algo do passado, para lembrar, situar ou revelar enigmas" (MACHADO, 2013, verbete "flashback").

5 Espécie de luta livre até a morte entre os escravos.
} 
impacto, uma exacerbação da tonicidade na medida em que apresenta o conteúdo polêmico da crueldade institucionalizada pelo sistema escravocrata tratado em um nível de figurativização acentuado. Essa estratégia acaba por arrebatar o enunciatário e evocar também o tema do sofrimento, relacionado à opressão e à injustiça.

Na cena em que Django precisa escapar de Candyland após a morte de Schultz, vemos que o enunciador do filme lança mão de uma estratégia para exacerbar a tonicidade no plano da expressão. Trata-se de uma combinação de vários cortes rápidos e tomadas em câmera lenta, nas quais o protagonista atira em dezenas de capatazes da fazenda. A trilha sonora em ritmo acelerado contribui também para esse movimento. Observamos que essa estratégia se repete em várias cenas de ação do filme. Os quadrinhos, no entanto, oferecem outros recursos para retratar essas mesmas sequências. Vejamos na figura 1, por exemplo, como a passagem em que Django mata um dos irmãos Brittle é reproduzida na revista:

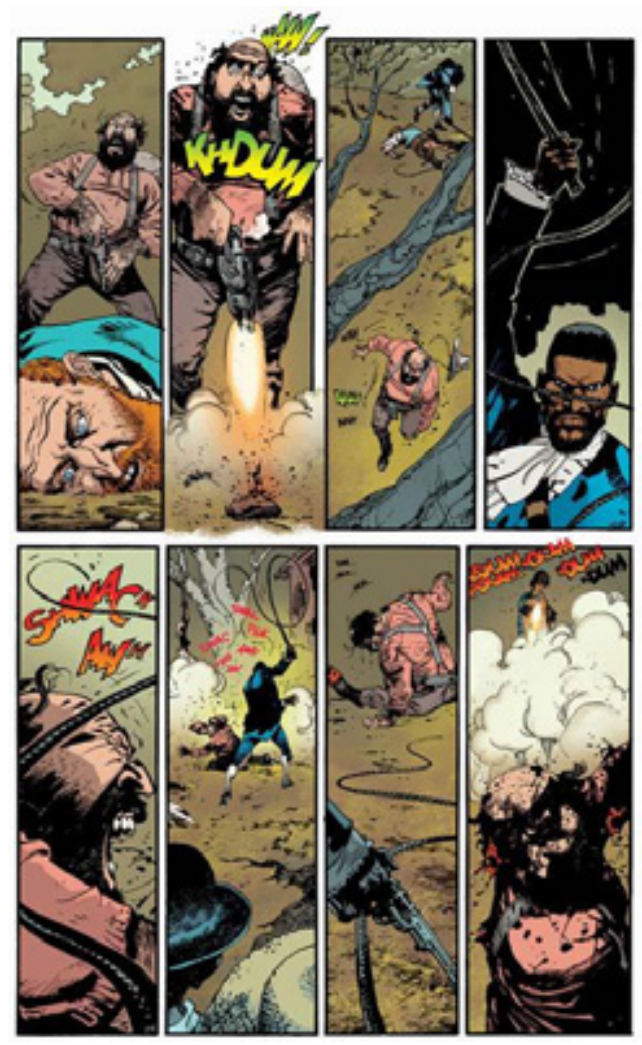

Figura 1. Cena em que Django ataca os irmãos Brittle nos quadrinhos Fonte: Django Unchained \#2 -p. 6

A revista divide a página em oito quadros retangulares e trabalha transições que mostram cada uma das ações dos personagens. A cena se desenrola em diferentes perspectivas, trazendo planos mais fechados e frontais. As curvas horizontais do chicote 
- Django livre: do cinema para os quadrinhos, uma tradução intersemiótica

de Django e as diagonais dos galhos da árvore (quadrinho 3) aparecem em contraste à organização vertical da página e transmitem, assim, uma ideia de movimento, reforçada pelas onomatopeias manifestadas no plano verbal. Nessas imagens, o enunciador explora um recurso que está presente tanto nas HQs ocidentais quanto nos mangás, como explica Cools (2011, p. 71) sobre as cenas de ação:

[...] linhas de movimento são exageradas nas cenas de combate para enfatizar a violência e/ou o movimento, onde linhas imaginárias convergem para destacar um ponto de foco em uma página. O resultado é que a informação principal da página é destacada pela sobredeterminação, e, portanto, é mais facilmente captada pelo olho.

Essas escolhas na revista em quadrinhos nos conduzem por uma estratégia de exacerbação, "simulando" os cortes rápidos e o dinamismo de uma cena de ação cinematográfica. Os closes que destacam os detalhes da cena criam os efeitos de sentido que, no filme, são construídos com a câmera lenta. Esse recurso simula a expansão do tempo cronológico, mas não por isso desacelera o andamento do texto, nesse caso. Causa, na verdade, certo desconforto ao enunciatário, que pode visualizar lenta e detalhadamente um golpe violento, o efeito de um tiro, um dilaceramento, uma explosão; eventos que são rápidos e tônicos por natureza.

Nas cenas de ação, vemos que o enunciador dos quadrinhos tentou manter o ritmo acelerado criado por Tarantino com seus cortes rápidos, câmeras lentas tonificantes e trilha sonora eletrizante por meio de recursos como o plano fechado, a desreferencialização espacial (fundo desfocado) e a construção de um efeito visual de movimento com elementos gráficos. Assim, a HQ opta por manter um andamento acelerado do conteúdo nessas cenas e constrói sua estratégia com base nos recursos que a linguagem em quadrinhos oferece.

Pensando a adaptação de forma mais global, percebemos que o paralelismo figurativo entre filme e quadrinhos é tão marcado que se estende à fisionomia dos personagens (desenhos semelhantes aos atores), aos figurinos, aos cenários e às falas, que são as mesmas do roteiro original. Essa estratégia cria uma identidade entre as obras, pautada pela lógica implicativa e, nessa perspectiva, manipula o enunciatário pelo conforto. 


\section{Um jogo de vozes}

É usual na linguagem dos quadrinhos que o balão comporte a fala dos personagens e as legendas comportem a fala do narrador (MCCLOUD, 1995). Como explica Ramos (2016), o balão de fala pode assumir diversas formas e usos, mas sua função de comportar a fala de um interlocutor é bem demarcada. Já as legendas apresentam, em geral, a fala de um narrador, mesmo quando ele é também personagem da história:

Defendemos que não é apenas o narrador onisciente que tem direito ao uso da legenda. O narrador-personagem também pode se apropriar do recurso. É comum em algumas histórias o aparecimento do rosto do personagem, de modo a identificá-lo como o narrador daquele trecho, geralmente fazendo menção a um fato do passado (ou flashback). (RAMOS, 2016, p. 50).

Esse esquema é seguido em boa parte das revistas Django Unchained e, inclusive, remete ao narrador expresso no plano verbal do filme. No entanto, há momentos em que as vozes dos personagens durante os diálogos aparecem nas legendas - e não nos balões - demarcadas por aspas, mesmo quando eles não assumem o papel de narradores (Figura 2). Essa mudança no quadrinho analisado provoca um sincretismo de vozes do narrador e do personagem (GREIMAS; COURTÉS, 2012, p. 467) ${ }^{6}$.

Nesse caso, as vozes de narrador e personagem se unem e se confundem. Vemos que esse sincretismo causa certo estranhamento ao enunciatário e o manipula pela concessão, já que é esperado que as legendas expressem a fala de um narrador. Ao mesmo tempo, causa certa confusão e demanda do leitor que ativamente decida, pautando-se nos elementos contextuais, se a legenda está expressando a fala de um narrador ou a de um personagem e, nesse caso, a qual personagem pertence.

6 O sincretismo, segundo Greimas e Courtés (2012, p. 467), é o procedimento por meio do qual se estabelece uma relação entre dois termos ou categorias heterogêneos, que são recobertos por uma grandeza semiótica que os reúne. 


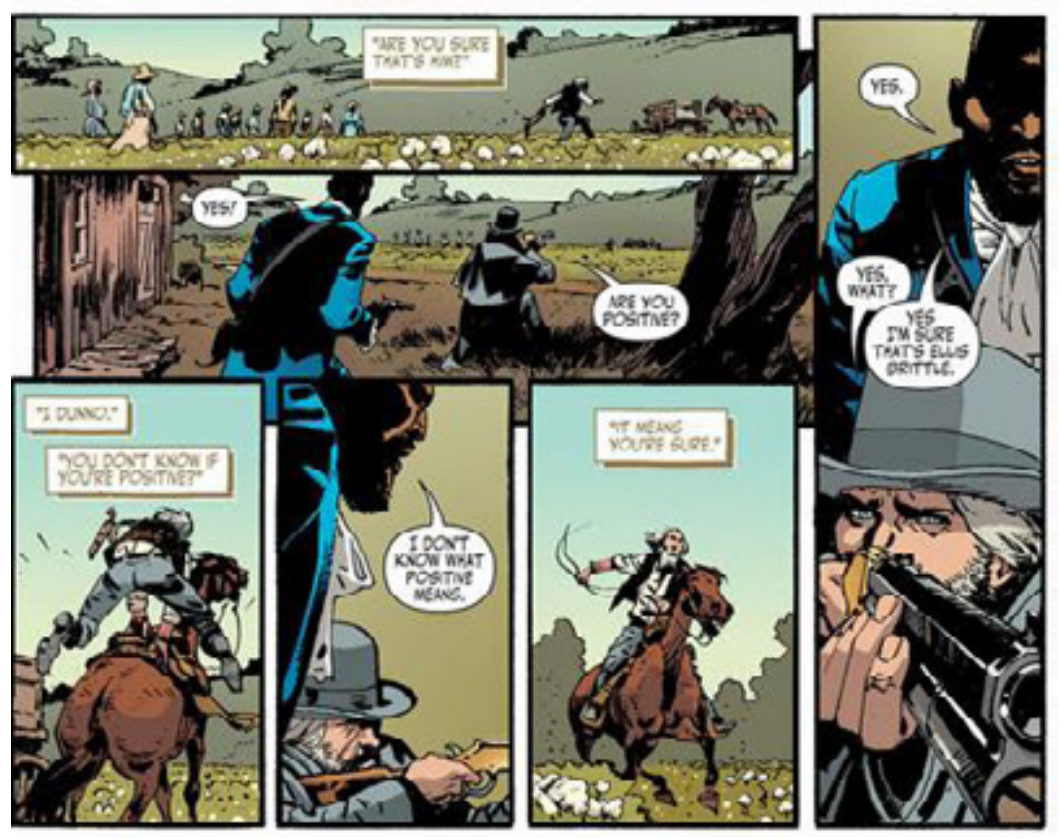

Figura 2. Jogo de vozes

Fonte: Django Unchained \#2, p. 6

Analisando os quadrinhos que utilizam essa estratégia(repetida em todas as revistas), percebemos que ela é empregada sempre que o personagem não está figurativizado explicitamente no quadrinho em questão. Logo, entendemos que o enunciador emprega esse recurso para remeter à locução em off da linguagem cinematográfica. Essa ferramenta específica do audiovisual se caracteriza por "vozes ou sons presentes sem se mostrar a fonte emissora" (MACHADO, 2013) ${ }^{7}$. Assim, a fonte daquela fala que não está manifestada no quadrinho não é mostrada.

No cinema, o recurso é muito usado justamente para comportar o discurso de um narrador que não aparece na tela. Esse uso já está sedimentado na linguagem cinematográfica e faz parte de suas potencialidades. Nos quadrinhos ele remete, portanto, à simulação de um recurso que pertence a outra linguagem. Além disso, quando se usa uma locução em off, deixa-se uma lacuna a ser preenchida, que diz respeito a quem fala e quando. A esse preenchimento chamamos "catálise", que é definida por Greimas e Courtés (2012, p. 54) como a "explicitação dos elementos elípticos ausentes na estrutura de superfície. É um procedimento que se realiza com o auxílio dos elementos contextuais manifestados e mediante as relações de pressuposição que entretêm com os elementos implícitos".

7 Disponível em: http://www.roteirodecinema.com.br/manuais/vocabulario.htm. Acesso em: 26 set. 2013. 


\section{Desenvolvendo a ação}

Neste momento de nossa análise, cabe uma breve reflexão sobre algumas características das linguagens envolvidas na relação de adaptação. Muitas são as abordagens possíveis em uma comparação entre a linguagem cinematográfica e a linguagem dos quadrinhos. Neste artigo, optamos por um recorte que compreende dois componentes comparáveis das duas linguagens envolvidas, que têm o mesmo objetivo de expressar as ações: a montagem no cinema e a transição entre quadros nos quadrinhos. Ambos podem nos apresentar diferentes pontos de partida para desenvolver o progresso narrativo. Não iremos, portanto, tratar de todo o sistema das duas linguagens, e, sim, tomar o aspecto de desenvolvimento da ação no cinema e nos quadrinhos como critério de comparação.

Da mesma forma que Zilberberg (2011) argumenta que, para a corrente tensiva, o andamento prevalece como senhor dos afetos, na linguagem cinematográfica, a montagem tem também uma posição de protagonismo. Embora tão intrínseca à linguagem a ponto de não a percebermos na maioria das vezes, é ela a principal ferramenta na criação do ritmo de um filme:

Poudovkine [...] declarou que a noção de montagem, além de todos os sentidos particulares que lhe damos (colagem de pedaços, montagem acelerada, princípio puramente rítmico, etc.), é na realidade o todo da criação fílmica: o "plano" não é um pequeno pedaço do cinema; é a matéria primária, fotografia do mundo real. Não avançamos da fotografia ao cinema, do decalque à arte, senão pela montagem. Amplamente definida, ela se confunde simplesmente com a própria composição da obra. (METZ, 1964, p. 53, tradução nossa).

Os cortes estabelecem um modus operandi próprio, que, no cinema hollywoodiano canônico, parece transparente a um espectador assíduo, mas que provocariam um estranhamento a alguém que nunca tivesse tido contato com essa linguagem. Em uma cena em que dois personagens conversam, a câmera ora se fecha em um, ora em outro (deixando a voz do primeiro em off), ora trabalha com um plano aberto, em que vemos os dois. A câmera é um narrador, que nos apresenta um ponto de vista e direciona nosso olhar. Os cortes pressupõem que o enunciatário preencha pequenas lacunas - que mais acima chamamos de catálises - e entenda que, ao focalizar uma personagem, ainda estamos no mesmo ambiente da conversa, onde a outra personagem a escuta, por exemplo. 
- Django livre: do cinema para os quadrinhos, uma tradução intersemiótica

Na linguagem cinematográfica, as catálises são constitutivas da montagem. Dizemos constitutivas porque a montagem já se estabeleceu como parte do sistema dessa linguagem. Em uma montagem mais convencional de obras hollywoodianas, as lacunas deixadas pelos cortes já são esperadas pelo enunciatário, e frequentemente parecerão transparentes ao espectador.

Quando falamos da catálise constitutiva demandada pela linguagem, tratamos de um pressuposto, de uma base, um paradigma da linguagem cinematográfica que foi se constituindo ao longo da história e que, como em todo sistema, vai se modificando conforme os usos, as novas possibilidades que são incorporadas a ele. Assim, se compararmos filmes do início da história do cinema com filmes atuais, veremos que essa morfologia foi se transformando. A catálise constitutiva foi se estabelecendo no sistema dessa linguagem por meio do uso recorrente e hoje se apresenta como uma práxis cristalizada do cinema.

Não queremos dizer, com isso, que não haja formas de inovar na montagem. Pelo contrário, muitos diretores adotam como estratégia subverter esses usos esperados da montagem, como, por exemplo, Christopher Nolan, em Amnésia (Memento, 2000), que investe em uma montagem que alterna duas sequências temporais da história, uma prospectiva e outra retrospectiva, marcadas por diferentes filtros, de modo a criar um embaralhamento temporal. Essa estratégia de montagem faz com que o início da narrativa seja apenas revelado no final e o espectador vá descobrindo aos poucos a trama que culminou na cena inicial.

Esses usos menos comuns causam um estranhamento no espectador, uma quebra de expectativas, e uma demanda maior de sua atenção. Diremos, com isso, que um filme cuja montagem subverte o canônico vai trabalhar com um andamento mais acelerado, ao contrário do andamento lento de uma montagem mais tradicional, cujas estratégias já estão cristalizadas numa práxis reconhecida.

No que diz respeito às questões rítmicas nos quadrinhos, há muito a dizer sobre o requadro e os arranjos rítmicos que dele decorrem. É bem conhecida a discussão de Groensteen (2015) sobre as funções do requadro, incluindo sua função rítmica, que aborda o papel dos intervalos, que permitem criar uma distribuição rítmica da narrativa.

Ignorar a velocidade (as imagens são imóveis e sem impressões de voz que permita a fluência dos diálogos) não sugere nada menos que uma leitura cadenciada, uma operação ritmada pelo cruzamento dos quadros. Seu discurso tem a particularidade de ser descontínuo, elíptico, agitado. Cada novo quadro precipita a narrativa e, simultaneamente, a contém. O requadro é o agente dessa dupla manobra de progressão/retenção. (GROENSTEEN, 2015, p. 55). 
Sem negar a importância do requadro na construção rítmica dos quadrinhos, gostaríamos, neste trabalho, de chamar a atenção também para o papel das transições e sua função de encadear as cenas. Assim como é possível montar cenas de diversas formas, é possível desenvolver as ações nos quadrinhos de diferentes maneiras, demandando mais ou menos catálises. Scott McCloud (1995, p. 67) não cita o termo catálise explicitamente, embora defina uma noção similar cunhada de "conclusão": "Os quadros das histórias fragmentam o tempo e o espaço, oferecendo um ritmo recortado de momentos dissociados. Mas a conclusão nos permite conectar esses momentos e concluir mentalmente uma realidade contínua unificada".

A partir dessa definição, McCloud estabelece seis tipos de transição entre quadrinhos de acordo com a maior ou menor presença de lacunas, ou seja, o grau de engajamento exigido do enunciatário. Tomaremos essa classificação por base, fazendo apenas algumas modificações ${ }^{8}$ para adequá-la a uma formulação semiótica e à concepção de catálise. Optamos por trabalhar com as transições de McCloud por seu encaminhamento processual, que se abre mais a uma aproximação com nosso arcabouço teórico-metodológico e permite uma reformulação tensiva. Propomos, assim, a partir do trabalho de McCloud, uma gradação tensiva de transições, da que demanda menos catálises àquela que demanda mais envolvimento do enunciatário no preenchimento de lacunas:

1) movimento-a-movimento: as transições são sequenciais e exigem poucas catálises. Essa transição aproxima os quadrinhos da linguagem cinematográfica no sentido de simular o movimento contínuo. No que diz respeito ao andamento, ela desacelera a narrativa. Na figura 3, a seguir, vemos exemplos do próprio McCloud (1995). A transição da primeira imagem mostra apenas o movimento da personagem fechando os olhos. Essa transição vai quadro a quadro apresentando os pequenos movimentos que compõem a progressão narrativa. Não é preciso que o enunciatário complete quase nada.

8 McCloud utiliza a seguinte ordem de transições: movimento-a-movimento; ação-a-ação; tema-a-tema; cena-a-cena; aspecto-a-aspecto; non-sequitur. Colocamos a transição aspecto-a-aspecto antes de tema-atema, pois entendemos que ela demanda menos preenchimento de lacunas por parte do enunciatário que as transições tema-a-tema, cena-a-cena e non-sequitur. Além disso, criamos a transição lance-a-lance, que não existe na tipologia de McCloud, para compreender uma transição mais acelerada do que a ação-a-ação, mas que ainda se ampare na mesma figurativização (diferente da transição tema-a-tema). 

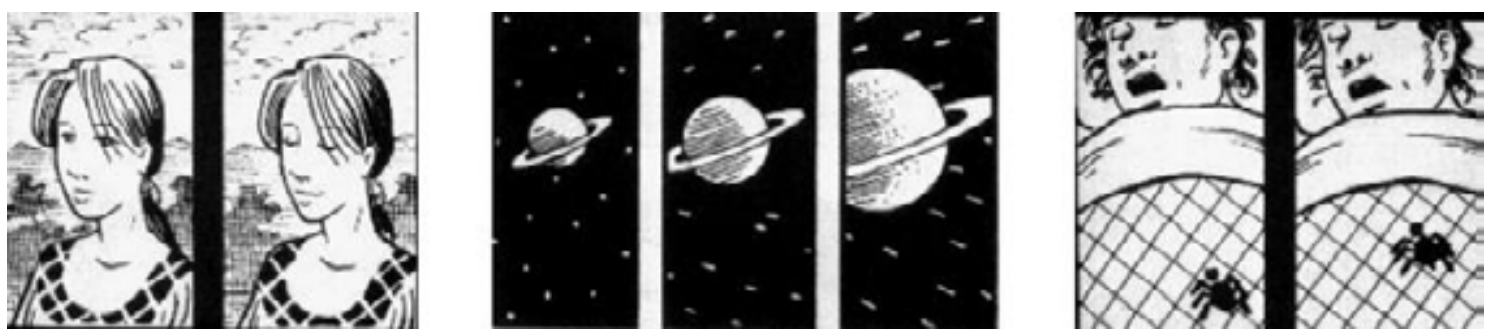

Figura 3. Exemplos de McCloud para transição movimento-a-movimento

Fonte: McCloud (1995)

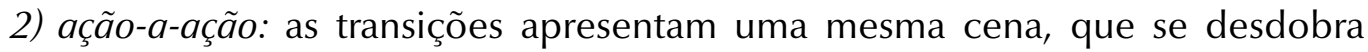
pelos quadrinhos ação-a-ação. Exigem mais envolvimento do enunciatário do que a classificação anterior, mas ainda não deixam muitas lacunas a serem preenchidas entre os quadrinhos. Na figura 4, temos os exemplos de McCloud para essa transição. Observemos que, na primeira imagem, o jogador de baseball aparece esperando para bater na bola no primeiro quadro e já batendo no segundo quadro. Não se trata de uma transição movimento-a-movimento porque não vemos a sequência do seu braço se aproximando da bola, apenas a ação de bater. Essa seria a pequena lacuna a ser preenchida.
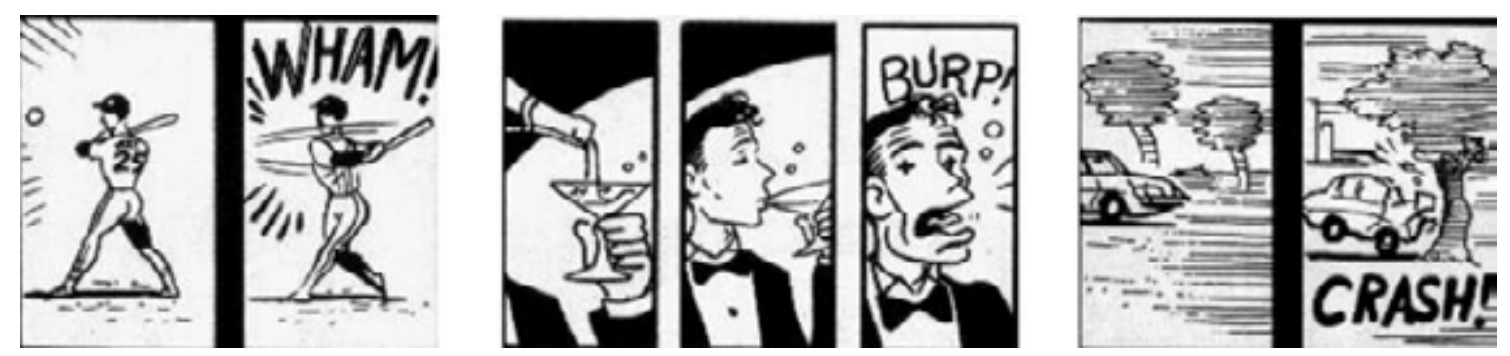

Figura 4. Exemplos de McCloud para a transição ação-a-ação

Fonte: McCloud (1995)

3) Lance-a-lance: Essa transição não existe na sequência estipulada por McCloud, mas sentimos necessidade de acrescentá-la para termos um intermediário entre a transição ação-a-ação e as demais. Assim, dentro do mesmo universo figurativo, a transição lancea-lance mostra o desenvolvimento de uma cena, mas deixa mais lacunas entre as ações. Na figura 5, temos um exemplo do que seria essa transição nos quadrinhos de The Walking Dead (KIRKMAN; MOORE, 2003). Vemos que, no segundo quadrinho, o policial está abrindo ou fechando a grade e, no terceiro, já aparece de volta ao carro, indo embora e sendo observado por um zumbi. Na transição lance-a-lance, estamos no mesmo plano no que diz respeito à figurativização, mas não vemos todas as ações, passo-a-passo; apenas o lance. Não vemos como é a passagem do segundo ao terceiro quadrinho. O policial tenta 
abrir a grade, o zumbi aparece, o assusta e ele corre, pega o carro e vai embora? Ou o policial fecha a grade e sai com o carro sem ver o zumbi que se aproxima? É o enunciatário que terá de deduzir isso tudo, porque os elementos apresentados não mostram essas ações claramente. Se o enunciador tivesse usado uma transição ação-a-ação, veríamos o zumbi surgindo e assustando o policial e este pegando o carro para ir embora ou o policial indo embora e só então ocorreria a aparição do zumbi. É por isso que essa transição é mais acelerada: ela deixa mais espaço de inferência.
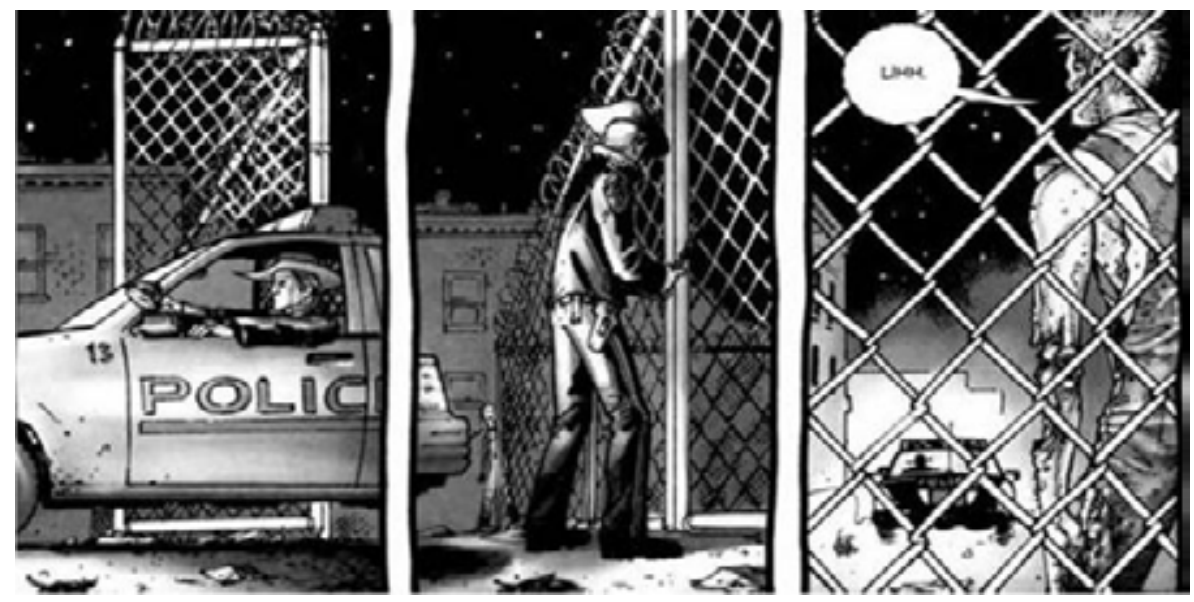

Figura 5. The Walking Dead

Fonte: Vol $1 \# 2$, p.24

4) aspecto-a-aspecto: essa transição funciona como uma espécie de "olho migratório", que percorre certo ambiente, mostrando detalhes e diferentes aspectos de uma cena, ideia ou atmosfera. Esse tipo de transição serve ao propósito de ambientar o leitor na narrativa. Por focar variados aspectos de uma cena, remete ao movimento de câmera no cinema em uma montagem tradicional. Trata-se de uma transição mais acelerada do que as anteriores não só pelas mudanças de perspectiva, que podem confundir um pouco o enunciatário, como pelas mudanças figurativas dentro de um mesmo tema. Vejamos os exemplos de McCloud (1995) na figura 6. No segundo exemplo, temos, primeiro, o sol com algumas árvores; depois, um homem de óculos escuros e, em seguida, o céu com nuvens e pássaros. Apesar de concretizar um mesmo tema, o enunciatário terá que fazer a ligação entre essas figuras para entender que se trata de um mesmo ambiente. Na transição anterior, lance-a-lance, as figuras da sequência de quadros apresentam traços semânticos comuns e, nesse sentido, o enunciatário é menos demandado em sua leitura: 

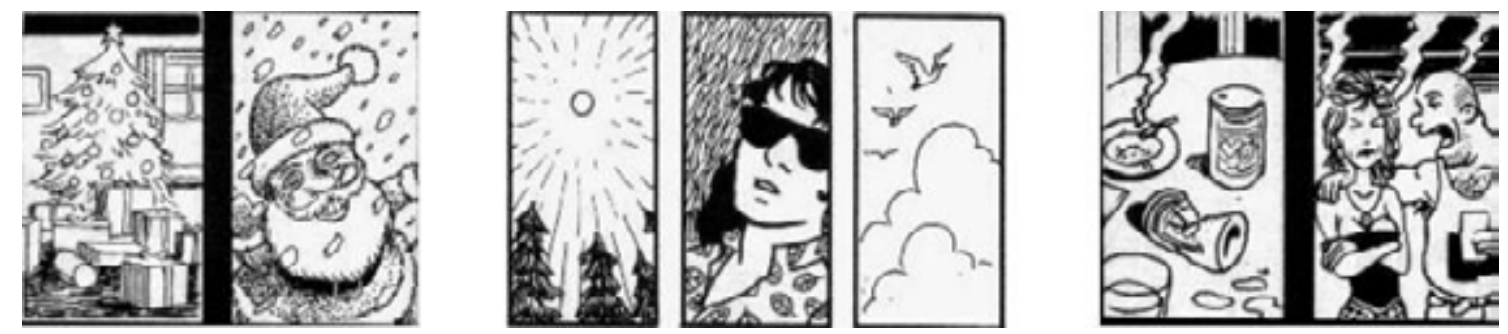

Figura 6. Exemplos de McCloud para a transição aspecto-a-aspecto

Fonte: McCloud (1995, p. 72)

5) tema-a-tema: dentro de um mesmo tema ou ideia, essa transição quebra a sequência, amplia a lacuna e exige que o enunciatário apresente maior engajamento para completar o ciclo dos quadrinhos. Essa transição amplia as possibilidades de leitura, pois apresenta outras figuras relacionadas ao mesmo tema, mas sem a sequencialidade de movimentos e ações se desenvolvendo. Diferentemente da transição anterior, as figuras agora não compõem necessariamente um mesmo ambiente, mas apenas uma mesma ideia, um mesmo tema geral. Trata-se de uma transição mais abstrata que a aspecto-aaspecto e que deixa mais lacunas a serem preenchidas pelo enunciatário. Vejamos os exemplos de McCloud na figura 7. No primeiro exemplo, temos o vilão pronto para desferir uma machadada no seu oponente. No quadrinho seguinte, não vemos o que aconteceu. A figurativização é de uma cidade e, apenas pela onomatopeia de um grito de dor, o enunciatário pode deduzir que o golpe foi dado. A ação não foi mostrada, por isso deixaram-se mais lacunas.
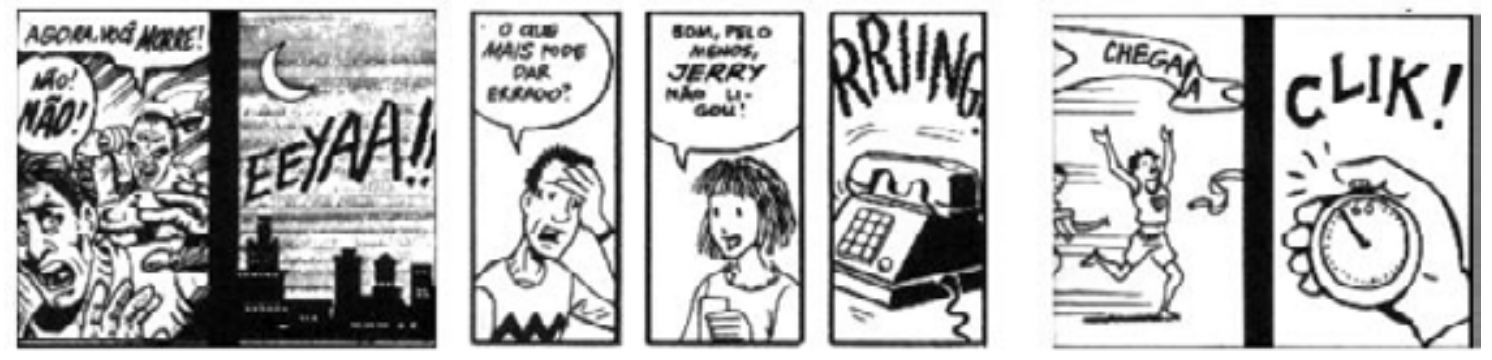

Figura 7. Exemplos de McCloud para a transição tema-a-tema

Fonte: McCloud (1995)

6) cena-a-cena: essa transição também exige um raciocínio dedutivo, apresentando distâncias maiores de tempo e espaço através dos quadrinhos. São sequências em que acontece uma grande passagem de tempo ("Dez anos depois"), acontecimentos simultâneos ("Enquanto isso") ou cenas em vários lugares e tempos diferentes dentro de um mesmo tema. Esse é o caso da tirinha da Turma da Mônica na figura 8. Vemos que os três personagens nos três primeiros quadrinhos estão em lugares e tempos diferentes. $\mathrm{O}$ 
enunciatário precisa se engajar para perceber isso, pois essa informação não está dada e apenas pode ser apreendida pelos elementos contextuais.
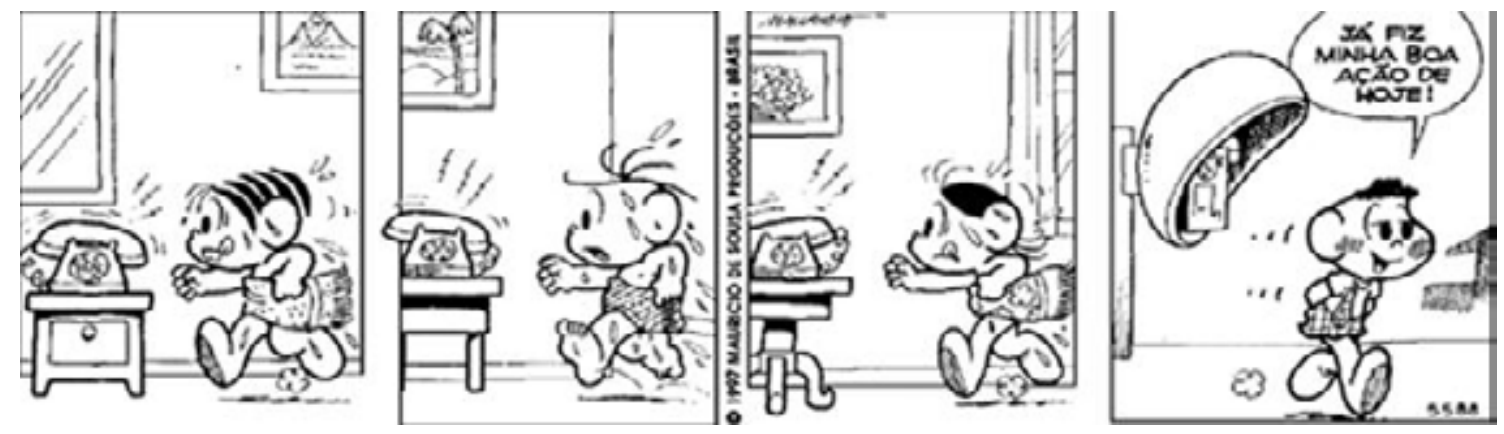

Figura 8. Turma da Mônica (1999)

Fonte: Turma da Mônica Online (Acesso em 5 fev. 2015)

7) non-sequitur: essa é a transição mais acelerada. Trata-se de quadrinhos que aparentemente não estão organizados em uma sequência lógica. Esse tipo é realmente difícil de encontrar e aparece apenas em algumas HQs de arte ou experimentais. Na figura 9, apresentamos alguns exemplos de McCloud (1995) do que seria essa transição.
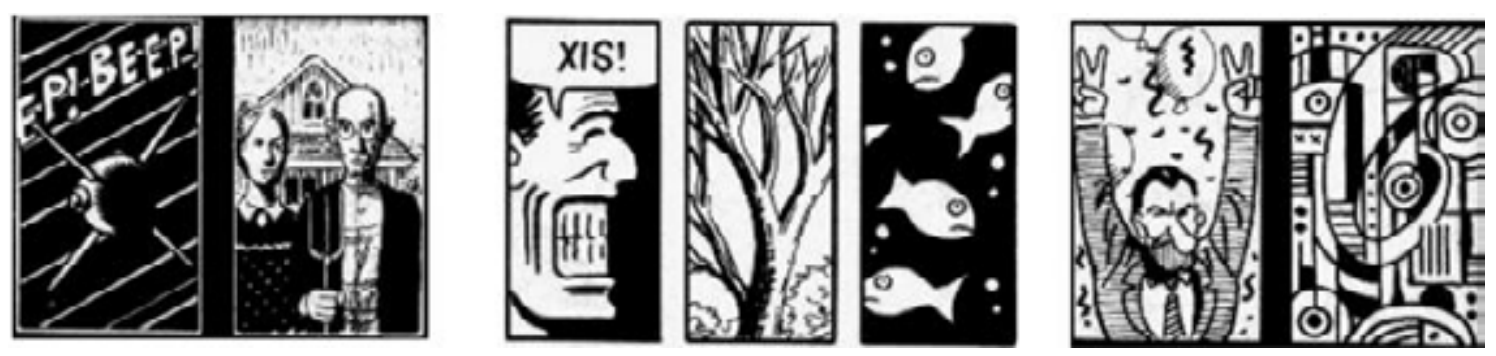

Figura 9. Exemplos de McCloud para a transição non-sequitur

Fonte: McCloud (1995, p. 72)

Todas as transições mostradas poderiam ter suas correspondências com o cinema em montagens narrativas: a movimento-a-movimento pode ser relacionada a cenas com planos longos; a ação- $a$-ação com um ritmo mais "natural" de desenvolvimento da ação; a lance-a-lance talvez com uma montagem mais dinâmica, que comprimisse os acontecimentos de um longo período em algumas cenas. A aspecto-a-aspecto, como já dissemos, representa os movimentos de câmera. Porém, transições como tema-a-tema e cena-a-cena, embora sejam possíveis no cinema, são muito mais raras e fazem parte de filmes que desafiam o senso comum. Nos quadrinhos, embora sejam transições mais aceleradas, elas são muito usadas, especialmente em tirinhas.

Vemos que os dois extremos de nossa gradação, movimento-a-movimento e nonsequitur, são transições pouco usadas nos quadrinhos e também estão fora da montagem 
- Django livre: do cinema para os quadrinhos, uma tradução intersemiótica

canônica do cinema. Filmes com planos longos, o que poderia ser a correspondência com a transição movimento-a-movimento, são tidos como lentos por grande parte dos espectadores; ao passo que filmes com montagens mais nonsense, que associam rapidamente figuras que não parecem ter relação, serão tidos como muito acelerados. Esses paroxismos vão ser empregados, em geral, tanto nos quadrinhos quanto no cinema em obras de cunho experimental.

Nesse sentido, podemos estabelecer que as transições ação- $a$-ação, lance- $a$ lance e aspecto-a-aspecto provocam um efeito maior de aproximação dos quadrinhos à linguagem cinematográfica tradicional, pois essas transições se relacionam diretamente com modos comuns de montagem dentro dessa práxis.

Pensando, ainda, nessa gradação de transições, podemos relacioná-la com os conceitos propostos pela abordagem tensiva, que nos permitirão instrumentalizá-la. Quando dizemos que uma transição exige mais ou menos catálise e com isso ela é mais ou menos acelerada, estamos pensando nos efeitos de sentido que essa construção evoca e nos modos de interação com o texto que ela propõe.

Essas formas de interação aconteceriam, segundo Zilberberg (2006), no espaço imaginário da tensividade, onde duas grandezas encontram-se em um estado de junção: a intensidade - esfera do sensível, dos estados de alma - e a extensidade - espaço do inteligível, dos estados de coisas ${ }^{9}$. Essa relação permite aferir as modulações nesse campo perceptivo e, assim, "mensurar" o elemento sensível. Permite, portanto, entender de que maneira se estabelecem e se desenvolvem os afetos, que passam a ser incorporados na teoria como elementos essenciais ao engajamento do enunciatário.

A partir dessa relação, a corrente tensiva propõe uma representação gráfica das dimensões - intensidade e extensidade - em dois eixos coordenados. A relação inversa entre os eixos se estabelece na grande maioria dos textos. Quanto maior for a intensidade, menor será a extensidade (ascendência) e, assim, o sujeito estará mais impactado e alcançará uma zona de arrebatamento (MANCINI; ALT, 2013). Na mesma linha, quanto menor for a intensidade, maior será a extensidade (descendência), o que criará cada vez mais um efeito de conforto para o sujeito.

Assim, um texto que preza pela concessão e que demanda mais de seu enunciatário trabalha com a predominância da intensidade. Podemos pensar a tipologia das transições

9 A intensidade divide-se nas subdimensões do andamento e da tonicidade, enquanto a extensidade é um sincretismo entre a temporalidade e a espacialidade. A extensidade circunscreve e demarca espacialmente e temporalmente o alcance do campo perceptivo controlado pela intensidade. Nessa linha, vemos que a intensidade rege a extensidade. O sensível conduz o inteligível. (ZILBERBERG, 2011). 
nesse esquema, de forma que quanto mais catálises uma transição demanda, mais elevada é sua intensidade e mais acelerado é seu andamento - sendo o andamento uma das subdimensões da intensidade. Nessa linha, estabelecemos as posições esperadas das transições no gráfico de acordo com sua proposta enunciativa. Notamos que as primeiras transições da gradação manipulam o enunciatário por uma lógica implicativa e as últimas apelam para o impacto de uma lógica concessiva. Isso está representado no Gráfico 1:

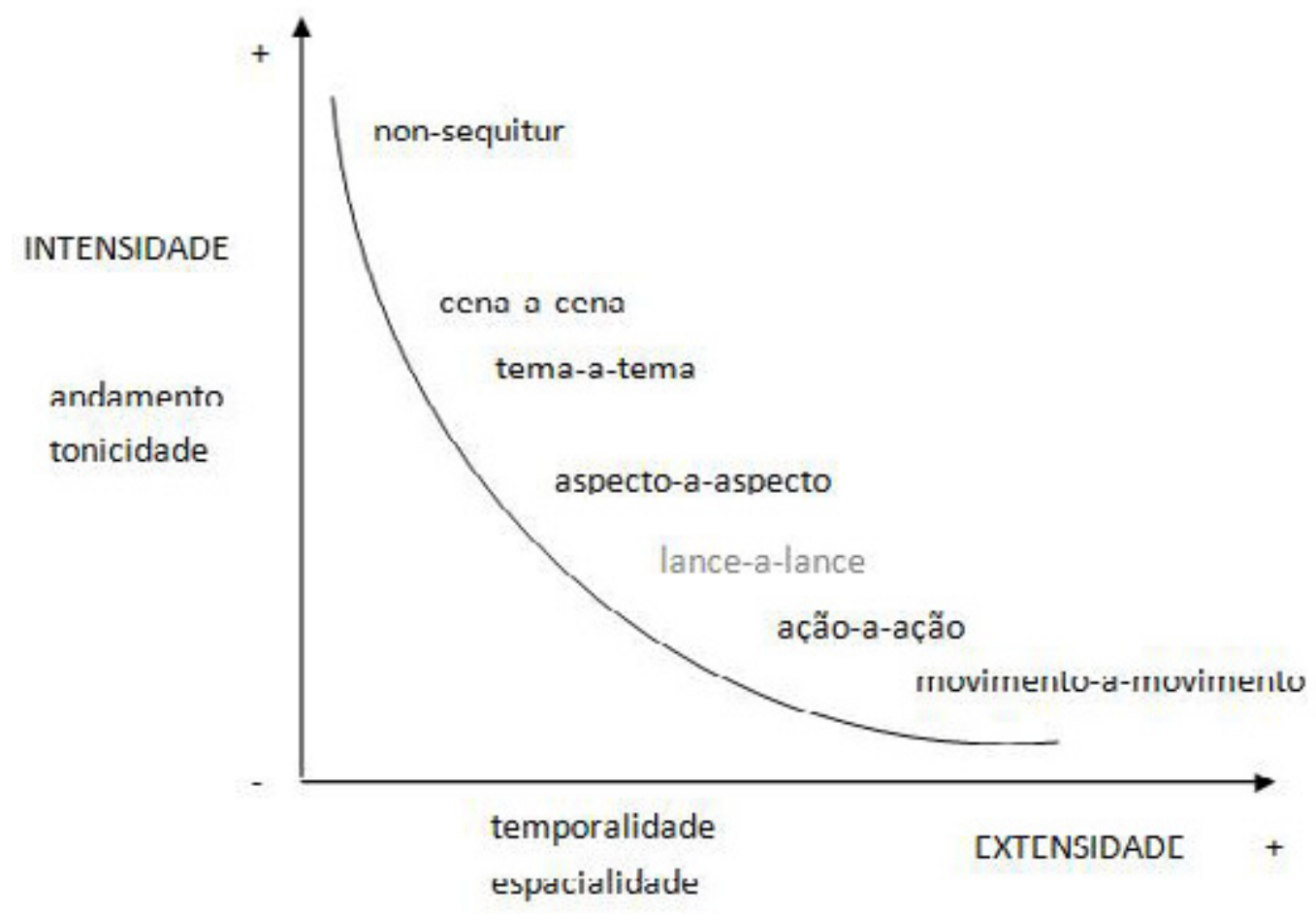

Gráfico 1. Transições dispostas no gráfico tensivo

Fonte: Elaboração própria

Com base nessa classificação, depreendemos, a princípio, uma análise um pouco mais atenta das duas primeiras revistas da série Django Unchained, com a intenção de mapear o uso dos diferentes tipos de transição. Observamos que, em algumas páginas, é utilizada mais de uma transição, enquanto outras transições estendem-se por longos trechos. Assim, nossa conta baseia-se em quantas vezes cada transição é utilizada de forma contínua, independentemente de compreender três ou dez quadrinhos. Observamos que as transições são combinadas nas duas revistas 63 vezes.

Nessa linha, quantificamos os tipos da seguinte forma: a transição ação-a-ação é a mais utilizada nas revistas \#1 e \#2, correspondendo a 46,3\% do total de transições; aspecto-a-aspecto vem em segundo lugar e corresponde a 39,6\%; a transição lance-a- 
- Django livre: do cinema para os quadrinhos, uma tradução intersemiótica

lance aparece principalmente nos flashbacks e equivale a $12,6 \%$ das transições totais; cena-a-cena aparece apenas uma vez e, assim, conta com apenas 1,5\% do total. Não encontramos as transições movimento-a-movimento, non-sequitur - os dois extremos de nossa gradação - nem a transição tema-a-tema.

Vemos, portanto, que os usos escolhidos pelo enunciador dos quadrinhos apontam para uma estratégia de aproximação com o filme, uma vez que são empregadas transições mais próximas às da montagem clássica hollywoodiana e deixadas de lado transições como cena-a-cena e tema-a-tema, que, por serem mais aceleradas, integram usos centrais e frequentes nos quadrinhos.

Daniele Barbieri (2017, p. 242), ao tratar das relações entre quadrinhos e cinema, afirma que a grande questão dos autores que procuram reconstruir o cinema nos quadrinhos é entender quais efeitos se consegue reproduzir e quais são pertinentes de serem reproduzidos, uma vez que, nesse tipo de reprodução, o papel central deve estar no segundo produto, nos próprios quadrinhos.

[...] nos quadrinhos que procuram reproduzir efeitos cinematográficos, esses efeitos de montagem são particularmente frequentes. Desse ponto de vista, o quadrinho de planejamento cinematográfico acaba por ser mais cinematográfico que o próprio cinema: como de costume, para que algo possa ser claramente reconhecível, suas características mais peculiares devem ser postas fortemente em evidência. (BARBIERI, 2017, p. 247).

\section{Considerações finais}

No início deste artigo, perguntamo-nos sobre as possíveis estratégias para uma tradução intersemiótica, levando em conta as particularidades de cada uma das linguagens envolvidas e, ao longo do texto, procuramos analisar especificamente como isso foi feito na adaptação de Django Livre para os quadrinhos. Vimos que o enunciador do novo produto buscou dar ênfase a um paralelismo de conteúdo, em que procurou manter o máximo possível de elementos narrativos, temáticos e figurativos do texto de partida. E, para além disso, ele se valeu de elementos da linguagem de partida (cinema) na elaboração do projeto discursivo da obra adaptada (quadrinhos).

O enunciador das HQs Django Unchained optou por transições menos aceleradas, simetria entre os quadros, entre outros recursos, o que indica que não apenas o conteúdo do filme foi recriado nos quadrinhos, mas também algumas características de expressão 
da linguagem cinematográfica. Pudemos observar isso em suas escolhas de contar as mesmas narrativas, recobertas pelos mesmos temas e figuras; no desenho simulando as feições dos personagens; no foco nas cenas de ação em que há a simulação do modo de enunciar de Tarantino nas telas; nas transições entre quadros mais próximas à montagem cinematográfica canônica; e, também, no jogo de vozes que simulava o off do cinema. Todos esses usos contribuíram para criar um simulacro da primeira linguagem na segunda: o cinema nos quadrinhos.

Nesse sentido, as conclusões de nossa análise vão ao encontro da hipótese mercadológica que propusemos no início do trabalho. Acreditamos que o enunciador dos quadrinhos se baseou no lançamento quase simultâneo dos dois produtos (o filme e a primeira revista) e procurou abarcar em suas estratégias o enunciatário do filme. Assim, a revista não esperava apenas atingir o público leitor de quadrinhos, mas o espectador de cinema que comprou a versão em quadrinhos para ver as cenas extras que não pôde assistir na sala de exibição.

Portanto, os quadrinhos contemplam, além do enunciatário de HQs, o perfil de enunciatário do filme, e, por isso, buscaram essa estratégia de simular a linguagem de partida na obra de chegada. A ideia seria deixar esse enunciatário confortável com a linguagem que já conhece e com a qual já está habituado. Deixá-lo confortável também com a história, que apenas se expande por meio do detalhamento de fatos já previstos pelo roteiro.

Em outras palavras, as escolhas das estratégias a serem postas em prática na tradução das primeiras revistas levavam em conta uma prática comercial englobante que procurou simular o filme nos quadrinhos, sobretudo para oferecê-lo como complemento do produto cinematográfico. Assim, de forma geral, acreditamos que, dentro da morfologia de base dos quadrinhos, a série de revistas de Django Unchained prioriza estratégias do fazer persuasivo que manipulam o enunciatário pelo conforto. Ressaltamos como o projeto enunciativo, que, neste caso, pretendia englobar o enunciatário da linguagem de partida, sempre influirá nas estratégias postas em prática no texto adaptado e em seu manejo rítmico e sensorial.

\section{Referências}

BARBIERI, D. As linguagens dos quadrinhos. São Paulo: Pereirópolis, 2017.

BARROS, D. Teoria semiótica do texto. São Paulo: Ática, 2011. 
- Django livre: do cinema para os quadrinhos, uma tradução intersemiótica

COOLS, V. The Phenomenology of Contemporary Mainstream Manga. Image \& Narrative, v. 12, n. 1, p. 63-82, 2011.

FONTANILLE, J. Discours, médias, pratiques et régimes de croyance. Texte de la conférence donnée à l'Université Fédérale Fluminense: Niterói, 2015.

GREIMAS, A. J.; COURTÉS, J. Dicionário de semiótica. São Paulo: Contexto, 2012.

GROENSTEEN, T. O sistema dos quadrinhos. Tradução Érico Assis e Francisca Ysabelle Manríquez Reyes. Nova Iguaçu: Marsupial Editora, 2015.

GUERA, R. M. Django Unchained 1-7. Vertigo \#1; DC Comics: New York, 2013.

HJELMSLEV, L. Prolegômenos a uma teoria da linguagem. Perspectiva, 1975.

KIRKMAN, R.; MOORE, T. Days Gone Bye. The Walking Dead, Diamond Comics, v. 1, \#1 e \#3, 2003.

MACHADO, J. Manuais On-line - Vocabulário do Roteirista. Roteiros de Cinema. Disponível em: http://www.roteirodecinema.com.br/manuais/vocabulario.htm. Acesso em: 26 set. 2013.

MANCINI, R.; ALT, J. Quadrinhos: do papel à internet. In: TEIXEIRA, L.; CARMO JR, J. R. do (org..). Linguagens na Cibercultura. São Paulo: Estação das Letras e Cores, 2013.

MCCLOUD, S. Desvendando os quadrinhos. Makron Books. São Paulo, 1995.

METZ, C. Le cinéma : langue ou langage ? Communications, Recherches sémiologiques, v. 4, p. 52-90, 1964. DOI: 10.3406/comm.1964.1028. Disponível em: http://www.persee. $\mathrm{fr} /$ web/revues/home/prescript/article/comm_0588-8018_1964_num_4_1_1028. Acesso em: 26 set. 2013.

RAMOS, P. A leitura dos quadrinhos. 2. ed. 2. reimp. São Paulo: Contexto, 2016.

SOUZA, M. Turma da Mônica, 1999. [on-line] Disponível em: http://www.monica.com. br/comics/tirinhas/tira42.htm e http://www.monica.com.br/comics/tirinhas/tira57. htm. Acesso em: 22 abr. 2013. 
TARANTINO, Q.; HUDLIN, R.; SHER, S.; SAVONE, P. Django Unchained [Filme-vídeo]. Los Angeles: Columbia Pictures, 2012. DVD/ NTSC, 165 min.

ZILBERBERG, C. Elementos de Semiótica Tensiva. São Paulo: Ateliê Editorial, 2011.

COMO CITAR ESTE ARTIGO: COUTINHO, Mariana de Souza e MANCINI, Renata Ciampone. Django livre: do cinema para os quadrinhos, uma tradução intersemiótica. Revista do GEL, v. 16, n. 1, p.143-163, 2019. Disponível em: https:// revistadogel.gel.org.br/

DOI: http://dx.doi.org/10.21165/gel.v16i1.2609

Submetido em: 12/09/2019 | Aceito em: 17/11/2019. 